08

\title{
Получение и исследование слоистых нанокомпозитов сульфид (селенид) цинка/диэлектрик
}

\author{
() С.С. Алалыкин, А.А. Дедюхин, Р.М. Закирова, В.Ф. Кобзиев, Н.В. Костенков, П.Н. Крылов, И.В. Федотова \\ Удмуртский государственный университет, \\ 426034 Ижевск, Россия \\ e-mail: ftt@udsu.ru
}

(Поступило в Редакцию 16 июня 2016 г.)

Исследованы слоистые нанокомпозиты $\mathrm{ZnS} / \mathrm{SiO}_{2}, \mathrm{ZnS} / \mathrm{Al}_{2} \mathrm{O}_{3}$ и $\mathrm{ZnSe} / \mathrm{SiO}_{2}$. Показано, что в области слабой дисперсии использование моделей Максвелла-Гарнета, Бруггемана и формулы Луйенги позволяет прогнозировать получение пленок с заданным эффективным показателем преломления. Расчетные значения показателей преломления достаточно хорошо коррелируют с экспериментальными данными. Максимальное отклонение теоретического значения показателя преломления от экспериментального и максимальное значение фактора деполяризации зависят от структуры и макронапряжений.

DOI: 10.21883/JTF.2017.05.44450.1934

\section{Введение}

Наноструктурированные системы в последние годы все чаще используют в качестве рабочих элементов при создании твердотельных химических и биологических сенсоров, каталитических систем, оптических и других устройств [1-4].

Для разработки различных устройств необходимо получение пленок с заданными характеристиками, в частности, с заданным значением диэлектрической проницаемости или показателем преломления. Варьировать характеристики пленок можно, задавая состав нанокомпозитов. Например, в [5] показано, что изменение концентрации наночастиц $\mathrm{ZnS}$ в оксидном стекле позволило модифицировать показатель преломления полученных стекол. Согласно [6], если характерные размеры составляющих компонентов нанокомпозитов меньше длины волны зондирующего излучения, то такой композит можно рассматривать как однородную оптическую среду, обладающую некоторым эффективным показателем преломления, отличным от показателей преломления веществ, образующих данный композит (модель эффективной среды). Изменение показателя преломления связано с изменением плотности материала, диэлектрической проницаемости и т.д.

Поиск новых нанокомпозитных материалов является перспективной задачей. Кроме того, возможности целенаправленного выбора соотношений концентраций составляющих композитов для получения материалов с заданными свойствами до конца не изучены.

Цель настоящей работы заключалась в получении и исследовании слоистых нанокомпозитов $\mathrm{ZnS} / \mathrm{SiO}_{2}$, $\mathrm{ZnS} / \mathrm{Al}_{2} \mathrm{O}_{3}$ и $\mathrm{ZnSe} / \mathrm{SiO}_{2}$. Задачей работы являлась также проверка применимости некоторых моделей для расчета значения эффективного показателя преломления нанокомпозитных пленок в зависимости от концентрации и показателей преломления исходных компонентов.

\section{Получение и методы исследования}

Для получения слоистых нанокомпозитов $\mathrm{ZnS} / \mathrm{SiO}_{2}$, $\mathrm{ZnS} / \mathrm{Al}_{2} \mathrm{O}_{3}$ и $\mathrm{ZnSe} / \mathrm{SiO}_{2}$ в качестве подложек использовались пластины плавленого кварца марки КУ-1. Подложки очищали в концентрированном щелочном растворе $\mathrm{NaOH}$, промывали дистиллированной водой. Чистоту подложки оценивали по смачиваемости поверхности водой.

Синтезировали нанокомпозиты методом ВЧ магнетронного напыления на установке Катод-1М. Для возможности позиционирования подложкодержателей относительно магнетронов и нагревателя и их сканирования по заранее заданной программе был разработан программно-аппаратный комплекс, использующий микросистему управления оборудованием [7]. Процесс формирования нанокомпозитных пленок включал в себя чередующиеся процессы напыления по заданной программе слоев сульфида или селенида цинка и диэлектриков. Толщина слоев диэлектриков в структурах не менялась. Менялось общее число пар $\mathrm{ZnS}(\mathrm{ZnSe}) /$ диэлектрик и толщина слоев $\mathrm{ZnS}\left(d_{\mathrm{ZnS}}\right)$ или $\mathrm{ZnSe}\left(d_{\mathrm{ZnSe}}\right)$. Число пар слоев выбиралось таким образом, чтобы обеспечить суммарную толщину пленок порядка $0.4 \mu \mathrm{m}$.

Предельное давление в камере составляло $3 \cdot 10^{-3} \mathrm{~Pa}$. Напыление проводилось в среде аргона при рабочем давлении $2 \cdot 10^{-1} \mathrm{~Pa}$. Температура подложек при напылении поддерживалась $150^{\circ} \mathrm{C}$. Распыление мишени $\mathrm{ZnS}$, $\mathrm{ZnSe}$ производилось при ВЧ мощности разряда $200 \mathrm{~W}$, a распыление мишеней $\mathrm{SiO}_{2}$ и $\mathrm{Al}_{2} \mathrm{O}_{3}$ при мощности $300 \mathrm{~W}$. После напыления образцы достигали комнатной температуры без разгерметизации вакуумной системы. Толщина слоев для $\mathrm{SiO}_{2}\left(d_{\mathrm{SiO}_{2}}\right)$ составляла $11.25 \AA$ а для $\mathrm{Al}_{2} \mathrm{O}_{3}\left(d_{\mathrm{Al}_{2} \mathrm{O}_{3}}\right)-8 \AA$.

В пленках $\mathrm{ZnS} / \mathrm{SiO}_{2}$ толщины $\mathrm{ZnS}$ составляли 7.8, 15.6, $23.4,31.2$ и $39 \AA$, а число пар слоев - 215, 152, 118, 96,81 . Процентное содержание диэлектрика в пленке составило при этом 59.0, 41.9, 32.5, 26.5 и 22.4\%. 
Пленки $\mathrm{ZnS} / \mathrm{Al}_{2} \mathrm{O}_{3}$ имели такие же толщины $\mathrm{ZnS}$ $(7.8,15.6,23.4,31.2$ и $39 \AA \AA)$, число пар слоев для достижения нужной толщины соответствовало 260,174 , 130, 104, 87. Процентное содержание диэлектрика в пленке составило при этом 50.6, 33.9, 25.5, 20.4 и 17.0\%.

В пленках $\mathrm{ZnSe} / \mathrm{SiO}_{2}$ толщины $\mathrm{ZnSe}$ составляли 12, $20,28,36,44$ и 52 , а число пар слоев - 200, 150, 114, $94,80,69$. Процентное содержание диэлектрика в пленке составило при этом 43, 31, 24, 20, 17, 15\%.

Толщину слоистых нанокомпозитных пленок и скорость роста отдельных слоев определяли с помощью МИИ-4 и по спектрам пропускания, которые имели осциллирующий характер, обусловленный интерференционными явлениями. Показатель преломления определяли по спектрам пропускания с использованием конвертного метода [8] и по спектрам отражения. Спектры оптического пропускания и отражения (диапазон $300-1100 \mathrm{~nm}$ ) регистрировали на спектрофотометpe CФ-56.

Структуру нанокомпозитных пленок исследовали методами рентгено-дифракционного анализа на автоматизированном дифрактометре ДРОН-3.0 [9] в монохроматическом излучении $\mathrm{Fe}-K_{\alpha}$ и просвечивающей электронной микроскопией на электронном микроскопе ЭМ-125.

\section{Экспериментальные результаты и их обсуждение}

Результаты измерения толщины пленок показали, что полученные образцы имеют заданную толщину $0.40 \pm 0.03 \mu \mathrm{m}$.

Согласно структурным исследованиям, пленки $\mathrm{ZnS} / \mathrm{SiO}_{2}$ являются аморфными, размер зерна, оцененный по микроизображениям, не зависит от толщины $\mathrm{ZnS}$ и составляет $\sim 3-4 \mathrm{~nm}$.

Структура пленок $\mathrm{ZnS} / \mathrm{Al}_{2} \mathrm{O}_{3}$ и $\mathrm{ZnSe} / \mathrm{SiO}_{2}$ зависит от толщины слоев полупроводника: при малых толщинах $\mathrm{ZnS}(\mathrm{ZnSe})$ пленки являются рентгеноаморфными, а при больших толщинах наблюдаются дифракционные максимумы, принадлежащие полупроводнику. Широкие дифракционные отражения, полученные для структур $\mathrm{ZnS} / \mathrm{Al}_{2} \mathrm{O}_{3}$, свидетельствуют о мелкой кристалличности пленок. Средний размер зерна в пленках $\mathrm{ZnS} / \mathrm{Al}_{2} \mathrm{O}_{3}$ практически не зависит от толщины $\mathrm{ZnS}$ и составляет $\sim 5-6 \mathrm{~nm}$. Для пленок $\mathrm{ZnSe} / \mathrm{SiO}_{2}$ на дифракционных кольцах электронограмм, соответствующих $\mathrm{ZnSe}$, наблюдаются рефлексы, свидетельствующие о наличии в слоях крупных кристаллов селенида цинка.

Пропускание нанокомпозитных пленок $\mathrm{ZnS} / \mathrm{SiO}_{2}$ и $\mathrm{ZnS} / \mathrm{Al}_{2} \mathrm{O}_{3}$ в области длин волн 450-1100 nm составляет 80-95\%. По спектрам пропускания и отражения был определен показатель преломления. Значение показателя преломления увеличивается с ростом толщины слоев (т.е. с увеличением процентного содержания) сульфида цинка (рис. 1, $a, b)$. Это коррелирует с результатами работы [5].
Спектры пропускания нанокомпозитных пленок $\mathrm{ZnSe} / \mathrm{SiO}_{2}$ не имеют ярко выраженной интерференционной картины. При этом в видимой области спектра
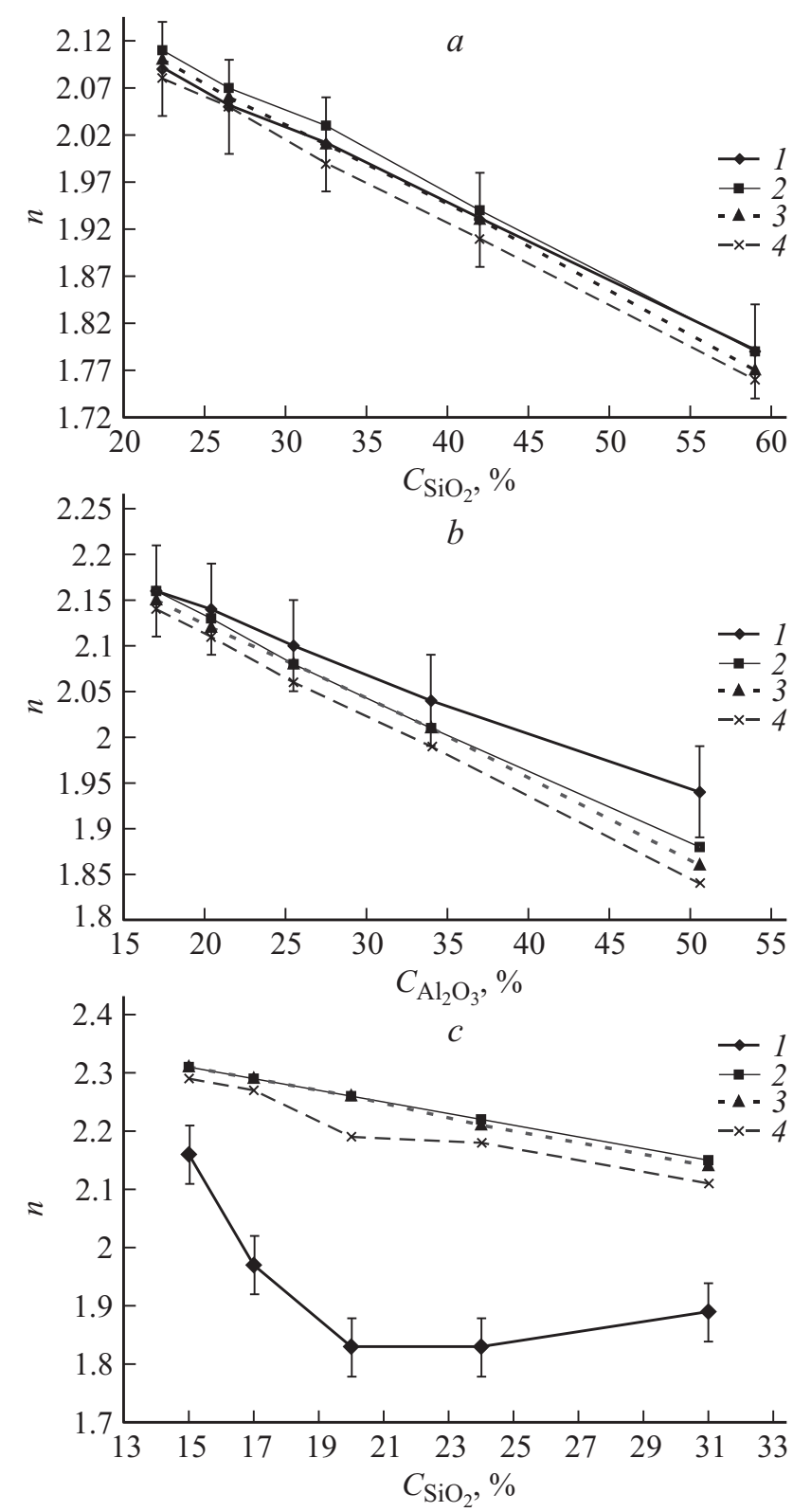

Рис. 1. $a-$ изменение показателя преломления нанокомпозитных систем $\mathrm{ZnS} / \mathrm{SiO}_{2}$ в зависимости от содержания диэлектрика в нанокомпозите: 1 - экспериментальные, $2-$ расчет по модели Максвелла-Гарнета, 3 - расчет по модели Бруггемана, 4 - расчет по формуле Луйенги; $b-$ изменение показателя преломления нанокомпозитных систем $\mathrm{ZnS} / \mathrm{Al}_{2} \mathrm{O}_{3}$ в зависимости от содержания диэлектрика в нанокомпозите: 1 - экспериментальные, 2 - расчет по модели Максвелла-Гарнета, 3 - расчет по модели Бруггемана, 4 расчет по формуле Луйенги; $c-$ изменение показателя преломления нанокомпозитных систем $\mathrm{ZnSe} / \mathrm{SiO}_{2}$ в зависимости от содержания диэлектрика в нанокомпозите: 1 - экспериментальные, 2 - расчет по модели Максвелла-Гарнета, 3 - расчет по модели Бруггемана, 4 - расчет по формуле Луйенги. 
пропускание нанокомпозитных пленок $\mathrm{ZnSe} / \mathrm{SiO}_{2}$ с увеличением процентного содержания $\mathrm{ZnSe}$ сначала уменьшается, а при дальнейшем увеличении процентного содержания селенида цинка (более $80 \%$ ) начинает возрастать. При росте толщины слоев селенида цинка начинают появляться на спектрах пропускания слабые осцилляции, которые могут косвенно говорить об улучшении структурного совершенства.

Для расчета значения эффективного показателя преломления нанокомпозитных пленок в зависимости от концентрации и показателей преломления исходных компонентов использовали модифицированные модели Максвелла-Гарнетта (известную также как формула Винера-Вагнера) [6]:

$$
\frac{\varepsilon_{\mathrm{eff}}-\varepsilon_{m}}{L\left(\varepsilon_{\mathrm{eff}}-\varepsilon_{m}\right)+\varepsilon_{m}}=f \frac{\varepsilon-\varepsilon_{m}}{\varepsilon_{m}+L\left(\varepsilon-\varepsilon_{m}\right)},
$$

Бруггемана

$$
f \frac{\varepsilon-\varepsilon_{\mathrm{eff}}}{\varepsilon_{\mathrm{eff}}+L\left(\varepsilon-\varepsilon_{\mathrm{eff}}\right)}+(1-f) \frac{\varepsilon_{m}-\varepsilon_{\mathrm{eff}}}{\varepsilon_{e f f}+L\left(\varepsilon_{m}-\varepsilon_{\mathrm{eff}}\right)}=0
$$

и формулу Луйенги

$$
\varepsilon_{\mathrm{eff}}^{\frac{1}{3}}=f \varepsilon^{\frac{1}{3}}+(1-f) \varepsilon_{m}^{\frac{1}{3}} .
$$

При этом считали, что приближенно можно использовать также выражение

$$
\varepsilon=n^{2}
$$

Здесь $\varepsilon_{\mathrm{eff}}-$ эффективная диэлектрическая проницаемость композитных пленок, $\varepsilon_{m}-$ диэлектрическая проницаемость полупроводника (в данном случае он является матрицей композита), $\varepsilon-$ диэлектрическая проницаемость диэлектрика (наполнителя композита), $f$ - доля наполнителя, $n-$ показатель преломления, связанный с диэлектрическими проницаемостями, $L-$ фактор деполяризации, учитывающий зависимость диэлектрической проницаемости от стратификации структуры.

На первой стадии расчетов считали, что нанокомпозит состоит из наночастиц сферической формы, помещенных в матрицу, т.е. $L=1 / 3$. При этом выражения (1) и (2) соответствовали классическим выражениям соответствующих моделей [6].

Для теоретического расчета значения эффективного показателя преломления проведенные дополнительные исследования показали, что при данных режимах напыления показатель преломления сульфида цинка составляет $2.30 \pm 0.05$, селенида цинка $-2.47 \pm 0.05$, показатель преломления $\mathrm{SiO}_{2}-1.44 \pm 0.05, \mathrm{a} \mathrm{Al}_{2} \mathrm{O}_{3}-$ $1.46 \pm 0.05$. Расчетные значения показателей преломления для пленок $\mathrm{ZnS} / \mathrm{SiO}_{2}$ и $\mathrm{ZnS} / \mathrm{Al}_{2} \mathrm{O}_{3}$ по формулам (1), (2) при $L=1 / 3$ и (3) в пределах погрешности совпали с экспериментальными значениями эффективного показателя преломления (рис. 1, $a-c$ ). Наибольшее отклонение наблюдалось для наименее прозрачных

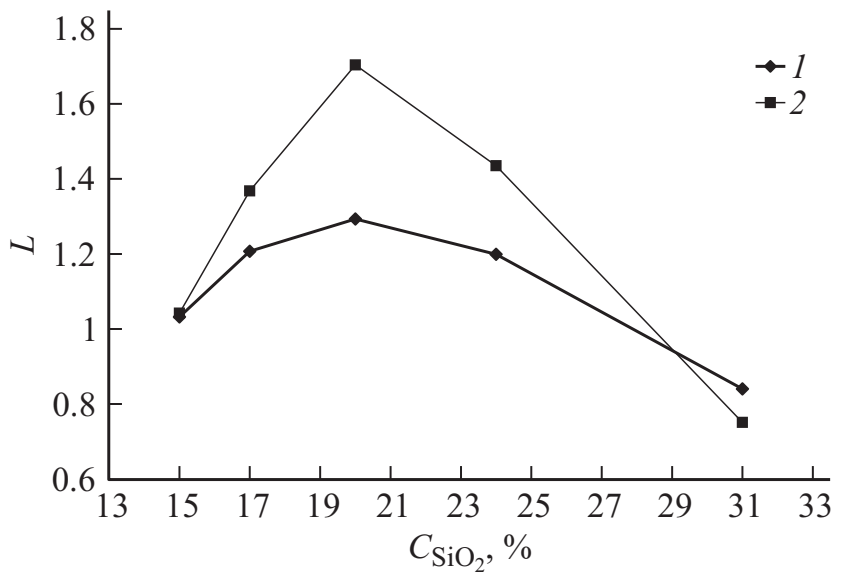

Рис. 2. Изменение фактора деполяризации $L$ в зависимости от содержания диэлектрика в нанокомпозите: 1 - расчет по модели Максвелла-Гарнета, 2 - расчет по модели Бруггемана.

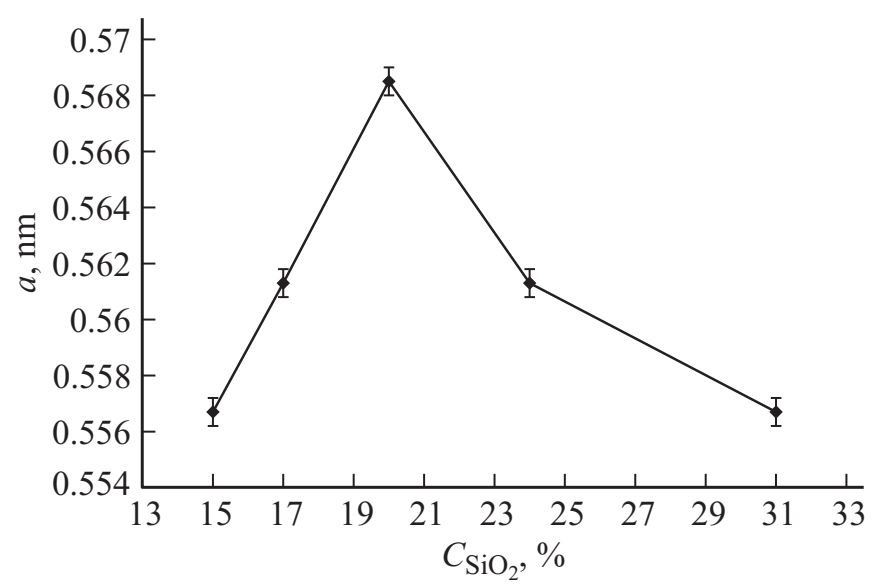

Рис. 3. Изменение параметра решетки $\mathrm{ZnSe}$ в зависимости от содержания диэлектрика в нанокомпозите.

пленок. Разница между расчетными по разным моделям и экспериментальными значениями показателей преломления для пленок $\mathrm{ZnSe} / \mathrm{SiO}_{2}$ составляла от 4.3 до $19 \%$. Максимальная разница наблюдается у пленок с минимальным пропусканием.

Зная эффективный показатель преломления, по выражениям (1) и (2) можно определить фактор деполяризации. Расчет показал, что для нанокомпозитов на основе сульфида цинка фактор деполяризации составил $1 / 3$. Можно предположить, что в данных структурах наночастицы сферической формы из аморфного $\mathrm{SiO}_{2}$ или $\mathrm{Al}_{2} \mathrm{O}_{3}$ помещены в матрицу сульфида цинка. Для нанокомпозитов $\mathrm{ZnSe} / \mathrm{SiO}_{2}$ фактор деполяризации меняется в зависимости от состава пленок (рис. 2). Максимальный фактор деполяризации наблюдается у пленок с минимальным пропусканием. Наличие фактора деполяризации может свидетельствовать о двулучепреломлении данных пленок. Согласно [6], двулучепреломление во многих средах может быть вызвано возникновением напряжений. 
По дифракционным картинам для данных пленок с использованием стандартной методики [10] были определены параметр решетки селенида цинка и макронапряжения $\left(\sigma_{1}+\sigma_{2}\right)$. Параметр решетки селенида цинка сначала увеличивается с ростом толщины слоев селенида цинка, затем уменьшается (рис. 3). Значение параметра решетки отличается от табличного значения $5.661 \AA$, что свидетельствует о наличии макронапряжений в исследуемых структурах. При относительно малой толщине слоев $\mathrm{ZnSe}$ макронапряжения положительные, т. е. являются растягивающими. С ростом толщины слоев уровень растягивающих напряжений уменьшается. При содержании диэлектрика 20\% макронапряжения становятся сжимающими. А при еще меньшем содержании оксида кремния макронапряжения снова становятся растягивающими. Величина макронапряжений минимальна для нанокомпозитных пленок с содержанием $\mathrm{SiO}_{2}$ 17\%.

\section{Заключение}

Методом ВЧ магнетронного напыления получены слоистые нанокомпозиты $\mathrm{ZnS} / \mathrm{SiO}_{2}, \mathrm{ZnS} / \mathrm{Al}_{2} \mathrm{O}_{3}$ и $\mathrm{ZnSe} / \mathrm{SiO}_{2}$ с суммарной толщиной $0.40 \pm 0.03 \mu \mathrm{m}$ и различным количеством пар слоев сульфида цинка и диэлектрика. Толщина слоев диэлектрика была постоянной. Толщина слоев сульфида цинка увеличивалась, в то время как число пар слоев уменьшалось.

Рентгенофазовый анализ и электронная микроскопия показали, что нанокомпозитные пленки $\mathrm{ZnS} / \mathrm{SiO}_{2}$ являются аморфными, размер зерна, оцененный по микроизображениям, не зависит от толщины прослойки $\mathrm{ZnS}$ и составляет $\sim 3-4 \mathrm{~nm}$. Структура пленок $\mathrm{ZnS}_{/} \mathrm{Al}_{2} \mathrm{O}_{3}$ и $\mathrm{ZnSe} / \mathrm{SiO}_{2}$ зависит от толщины слоев полупроводника: при малых толщинах $\mathrm{ZnS}(\mathrm{ZnSe})$ пленки рентгеноаморфные, при бо́льших толщинах наблюдаются дифракционные максимумы, принадлежащие полупроводнику.

По оптическим спектрам пропускания и отражения были определены толщины и показатель преломления полученных нанокомпозитных пленок.

Проверена применимость моделей Максвелла-Гарнета и Бруггемана, а также формулы Луйенги для расчета значения эффективного показателя преломления нанокомпозитных пленок. В области слабой дисперсии расчетные значения эффективных показателей преломления достаточно хорошо коррелируют с экспериментальными данными. Для поглощающих пленок отклонение теоретического значения показателя преломления от экспериментального возрастало при увеличении поглощения пленок.

Работа выполнена в рамках базовой части госзадания.

\section{Список литературы}

[1] Терехин В.В., Дементьева О.В., Рудой В.М. // Успехи химии. 2011. Т. 89. Вып. 5. С. 477-494.

[2] Климов В.В. // УФН. 2008. Т. 178. Вып. 8. С. 875-880.
[3] Stewart M.E., Anderton C.R., Thompson L.B., Matia J., Gray S.K., Rogers J.F., Nuzzo R.G. // Chem. Rev. 2008. Vol. 108. P. 494-521.

[4] Ролдугин В.И. // Успехи химии. 2004. Т. 73. Вып. 2. C. $123-156$.

[5] Saoudi R., Moussaoui M., Tonchev S., Tishchenko A.V. // J. Quant. Spectr. Radiat. Transfer. 2012. Vol. 113. N 18. P. 2499-2502.

[6] Головань Л.А., Тимошенко В.Ю., Кашкаров П.К. // УФН. 2007. Т. 177. Вып. 6. С. 619-638.

[7] Алалыкин С.С., Крылов П.Н. // ПТЭ. 2009. № 5. C. 160-161.

[8] Брус В.В., Солован М.Н., Майструк Э.В., Козярский И.П., Марьянчук П.Д., Ульяницкий К.С., Rappich J. // ФТТ. 2014. Т. 56. Вып. 10. С. 1886-1890.

[9] Алалыкин С.С., Крыллов П.Н. // ПТЭ. 2005. № 2. C. $149-150$.

[10] Горелик С.С., Скаков Ю.А., Расторгуев Л.Н. Рентгенографический и электронно-оптический анализ. М.: МИСИС, 2002. $328 \mathrm{c}$. 